ISSN 1392-3196 / e-ISSN 2335-8947

Zemdirbyste-Agriculture, vol. 106, No. 2 (2019), p. 183-190

DOI 10.13080/z-a.2019.106.024

\title{
Proteomic studies of honeybee- and manually-collected pollen
}

\author{
Veronika BORUTINSKAITE ${ }^{1}$, Gražina TREIGYTE ${ }^{1}$, Dalius MATUZEVIČIUS ${ }^{2}$, \\ Violeta ČEKSTERYTE ${ }^{3}$, Bogumila KURTINAITIENE ${ }^{1}$, Artūras SERACKIS², \\ Dalius NAVAKAUSKAS ${ }^{2}$, Rūta NAVAKAUSKIENE ${ }^{1}$ \\ ${ }^{1}$ Vilnius University, Life Sciences Center \\ Sauletekio 7, Vilnius, Lithuania \\ ${ }^{2}$ Vilnius Gediminas Technical University, Faculty of Electronics \\ Naugarduko 41, Vilnius, Lithuania \\ ${ }^{3}$ Lithuanian Research Centre for Agriculture and Forestry, Institute of Agriculture \\ Instituto 1, Akademija, Kèdainiai distr., Lithuania \\ E-mail: violeta.ceksteryte@lammc.lt
}

\begin{abstract}
In this study a new approach to quantitative and qualitative proteomic evaluation of pollen of different botanical origin was proposed. A monofloral mixture of plum (Prunus) $-86.83 \pm 0.70 \%$ and willow (Salix spp.) $-13.7 \pm$ $0.30 \%$ pollen, and monofloral plum (Prunus) pollen collected by bees was studied. Other pollen was collected manually from pear (Pyrus communis), apple tree (Malus sylvestris), cherry (Prunus / Cerasus) and wild cherry (Prunus avium). Samples were made during an early spring plant blossom. Proteins isolated from pollen samples were fractionated by a two-dimensional electrophoresis (2-DE) and about 50 proteins were identified using mass spectrometry analysis. A three-dimensional (3-D) visualization of proteins was performed. The intensities of protein spots differed in the orchard pollen samples more than ten times. The biological functions of the identified proteins differ, i.e. they are involved in transcription / translation, metabolic and other cellular processes.

The data revealed up-regulated process of the enzyme 5-methyltetrahydropteroyltriglutamate-homocysteine methyltransferase 1 in all pollen involved in methionine formation, which was the highest in monofloral orchard pollen collected by bees. This enzyme was identified in all the tested pollen. High level of expression of putative flavin-containing monooxygenase FMO GS-OX-like 11 protein was found in manually-collected pollen. This protein is important for plant protection against pathogens as well for plant hormone biosynthesis.
\end{abstract}

Key words: 2-D electrophoresis, 3-D visualization, mass spectrometry, pollen, proteins.

\section{Introduction}

Bee pollen has been recommended as a valuable dietary supplement, especially after surgery, to children with loss of appetite and to people working hard physically and mentally. Pollen has anti-inflammatory, detoxifying, antibiotic and sometimes even anti-allergic activity. All these properties are due to the unique composition of pollen (Komosinska-Vassev et al., 2015).

There are marked differences in the composition and content of carbohydrates between manuallycollected pollen and pollen pellets (Conti et al., 2016). In the pollen collected from anthers of 15 studied plant species, the content of total carbohydrates varied in range from $1.22 \%$ to $5.76 \%$ and protein content - from $11.20 \%$ to $48.40 \%$ (Tidke, Nagarkar, 2015). Sugar content in pollen pellets ranged from $21.77 \%$ to $58.95 \%$ and protein content - from $13.8 \%$ to $30.4 \%$ (Conti et al., 2016).

Proteomic analysis is used in pollen germination research. It was found that carbohydrate / energy metabolism, wall metabolism, protein synthesis, degradation and signalling was overrepresented in the mature pollen of Oryza sativa L. ssp. japonica (Dai et al., 2006). In the latter research there were identified 322 unique proteins, $23 \%$ of them having more than one isoform. It can be supposed that carbohydrates are essential for energy metabolism in anther of plant pollen. Honeybee foragers collect pollen grains from flowers, moisten them with nectar and mouth secretions, and so transform to "bee pollen". Addition of carbohydrates during the pollen collection process by bees changes pollen weight and influences pollen enzymatic modifications (Mauriello et al., 2017).

Protein content in pollen pellets is speciesdependent, while sugar content is not species-specific. Foragers add between 4.3 and $44.4 \mu \mathrm{M}$ sugar $\mathrm{mg}^{-1}$ pollen load. The content of this component added to pollen grain is associated with pollen dimensions and weight as well as environmental factors (Leonhardt, Blüthgen, 2012). Pollen proteins are composed of eighteen amino acids, including essential amino acids vital for bee diet: methionine, tryptophan, arginine, lysine, histidine,

Please use the following format when citing the article:

Borutinskaitė V., Treigytė G., Matuzevičius D., Čeksterytė V., Kurtinaitienė B., Serackis A., Navakauskas D., Navakauskienė R. 2019. Proteomic studies of honeybee- and manually-collected pollen. Zemdirbyste-Agriculture, 106 (2): $183-190$. DOI 10.13080/z-a.2019.106.024 
phenylalanine, isoleucine, threonine, leucine and valine (Negrao, Orsi, 2018). Studies show that nutritional needs of young bees for essential amino acids are greater compared to foragers (Paoli et al., 2014).

Kędzia (2008) has found nucleoproteins, such as histones, protamines, albumins and globulins, in pollen; the latter compounds are associated with nucleic acids. Pollen contains from $0.6 \%$ to $4.8 \%$ of nucleic acid. The author suggests that deoxyribonucleic acid (DNA) is concentrated in the nuclei of pollen cells of a generative nature, while ribonucleic acid (RNA) was identified in the nuclei of pollen cells of a vegetative nature.

There is little published data regarding proteomic studies of orchard pollen. Wang et al. (2018) have identified differentially expressed proteins among the pollen from the 'Snowdrift' crabapple, 'Hongling' crabapple, 'Hongjin' crabapple and 'Gala' apple trees. The authors have reported that differentially expressed proteins found in pollen are involved in these functions: metabolism related proteins, stress regulatory proteins and proteins involved in signal transduction. Proteomic analysis was used for the evaluation of changes in the apple fruit during different stages of ripening, maturation and senescence and the quality of apple (Shi et al., 2014)

Holmes-Davis et al. (2005) have identified 135 distinct proteins in Arabidopsis thaliana (Columbia ecotype) pollen that are involved in different processes like metabolism, energy generation or cell structure. Other studies quantified Arabidopsis pollen coat proteome and buckwheat (Fagopyrum esculentum) honey proteome (Mayfield et al., 2001).

Honeybee-collected pollen from tea tree (Camellia sinensis), preserved at room temperature and at $-20^{\circ} \mathrm{C}$, was subjected to protein composition analysis (Li et al., 2008). Proteins in the pollen were separated by a two-dimensional electrophoresis (2-DE) in a sodium dodecyl sulphate-polyacrylamide gel (SDS-PAGE) system (2D-PAGE) and identified using a matrix-assisted laser desorption / ionization time of flight (MALDI-TOF) mass spectrometry (MS) analysis and other methods. The authors identified more proteins in frozen pollen compared to the pollen preserved at room temperature and stated that storage conditions affected the protein abundance in the tested pollen samples.

The variation of protein expression in pollen manually-collected from the red clover cultivar 'Vyčiai', berseem clover 'Faraon' and white clover 'Medūnai', analysed by a mass spectrometry previously was investigated (Treigytè et al., 2014). Pollen was stored at $-80^{\circ} \mathrm{C}$ until analysis. Over 30 protein spots whose quantitative levels were most divergent in created and investigated clover pollen proteome map was detected. By means of MALDI-TOF mass spectrometry (MS/MS), analysis was performed in buckwheat honey. A total of 87 proteins were identified in this kind of honey. Using the native PAGE analysis method catalase and glucose oxidase activity in buckwheat honey was estimated (Borutinskaite et al., 2018).

The aim of present study was to develop a reference map of the bee- and manually-collected orchard pollen proteome using protein extraction technique followed by a two-dimensional electrophoresis (2-DE) and a mass spectrometry analysis and to compose a three-dimensional (3-D) visualization of protein spots, and characterize the potential functions of proteins and their expression.

\section{Materials and methods}

Honeybee-collected orchard pollen. All pollen samples were collected in the apiaries of Institute of Agriculture, Lithuanian Research Centre for Agriculture and Forestry, located in Kèdainiai district, Lithuania. Orchard pollen gathered by bees was collected in accordance with good beekeeping practices and did not interfere with normal colony growth (Gracham, 1992). Pollen gathered by honeybees was collected with a standard pollen trap purchased from the company "Wilara" (Lithuania). The trap was mounted on the hive entrance and pollen was collected in good weather during fruit tree blossoming. After removal from traps, the pollen was cleaned. One half of the bee-collected orchard pollen was marked as G1, and the other sample G2 was selected by colour and composed from G1. Botanical origin of G1 and G2 samples was confirmed microscopically. Botanical origin was determined by comparison of light microscopic images of pollen found in pollen samples to those of known pollen manually-collected (Čeksteryte, 2012). The G1 sample consisted of $86.83 \pm 0.70 \%$ plum (Prunus) and $13.7 \pm 0.30 \%$ willows (Salix spp.) pollen, and G2 sample consisted of $100.0 \%$ plum pollen. All samples were kept in a refrigerator at $-80^{\circ} \mathrm{C}$ in air-tight plastic bags until analysis.

Manually-collected pollen. Pollen samples were collected during early spring blossom of different fruit trees during 2013-2016. Pollen was collected from approximately 100-200 flowers picked from orchard trees. Samples of manually-collected pollen were composed from fruit plants: pear (Pyrus communis) (G3), apple tree (Malus sylvestris) (G4), cherry (Prunus / Cerasus) (G5), plum (Prunus) (G6) and wild cherry (Prunus avium) (G7). Pollen grains were manually-collected into Eppendorf tubes (Eppendorf AG, Germany) and immediately placed in a storage at $-80^{\circ} \mathrm{C}$ until analysis. The amount of pollen collected was $50-70 \mathrm{mg}$ per sample, each sampling was repeated three times.

Pollen expression results. About 400-500 pollen grains were counted in each sample. The frequency of pollen of each melliferous plant is expressed as percentage of the total pollen sum. Pollen considered as monofloral is mainly produced from one plant species or pollen content from one plant species is predominant (constituting more than $45.0 \%$ ). The pollen content of other plant species is designated as follows: secondary pollen $16-45 \%$; important minor pollen $3-15 \%$; minor pollen. This methodology is applied for the determination of honey pollen botanical composition (Louveaux et al., 1978). The same methodology and range of pollen levels are used to evaluate botanical composition of bee-collected pollen and beebread (Almeida-Muradiana et al., 2005; Čeksterytè et al., 2016). Manually-collected pollen was of $100 \%$ purity; therefore, the data from those samples were not subjected to statistical analysis.

Protein isolation from pollen. Proteins from mature pollen (approx. $20 \mathrm{mg}$ ) were isolated as described by Sheoran et al. (2007) with some modifications (Treigyte et al., 2014). Shortly, mature pollen was homogenized with acetone containing $10 \%$ trichloroacetic acid (TCA) and 1\% dithiothreitol (DTT). The solution was centrifuged $20.000 \times \mathrm{g}$ for $20 \mathrm{~min}$ at $4{ }^{\circ} \mathrm{C}$ and pellet was washed two more times with acetone solution containing $1 \%$ DTT. The pellet was dried in vacuum and proteins were extracted with isoelectric focusing (IEF) lysis buffer containing $9 \mathrm{M}$ urea, $2 \mathrm{M}$ thiourea, $4 \%$ CHAPS (3-[(3-cholamidopropyl)dimethylammonio]-1propanesulfonate), 1\% DTT, $0.8 \%$ IPG (immobiline $\mathrm{pH}$ gradient) buffer, $\mathrm{pH} 3-10$. The solution was centrifuged $20.000 \times \mathrm{g}$ for $20 \mathrm{~min}$ at $4^{\circ} \mathrm{C}$ and pellet was extracted again with IEF lysis buffer. After centrifugation, both extracts were combined, quantified (3-3.5 mg per $20 \mathrm{mg}$ pollen) using the BioRad DC protein assay kit (Bio-Rad Laboratories, USA) and directly used for protein analysis or stored at $-20^{\circ} \mathrm{C}$ until analysis. Three independent biological experiments were carried out.

Protein fractionation by two-dimensional electrophoresis $(2-D E)$. Proteins isolated from bee- and manually- 
collected pollen were resolved by 2-DE gel isoelectric point (pI) 3-11, gel gradient $7.5-20 \%$. Areas of interest were cut out from the 2-DE gel and subjected to overnight in-gel tryptic digestion (Shevchenko et al., 1996; Treigyte et al., 2014).

Mass spectrometry analysis. For matrix-assisted laser desorption / ionization time of flight (MALDI-TOF) analysis, the peptides were dissolved in $3 \mu \mathrm{l}$ of $30 \%$ acetonitrile and $0.01 \%$ trifluoracetic acid and were then prepared with a matrix (a-cyano-4-hydroxycinnamic acid) on the target plate. The analysis was performed in a 4800 MALDI TOF/TOF analyser (Applied Biosystems/ MDS SCIEX, Canada), which was externally calibrated using synthetic peptides with known masses. Mass spectrometry (MS) reflector mode setting was: $\mathrm{m} / \mathrm{z}$ range 800-4000, tandem mass spectrometry (MS/MS) mode settings were: collision energy $1 \mathrm{keV}$, collision-induced dissociation (CID) not used, fragment mass accuracy $\pm 0.1 \mathrm{Da}$. The mass information generated from the composite spectrum was submitted to a search performed with the free available UniProt database (The UniProt Consortium, UK).

Image acquisition and data analysis. Stained 2-DE gels were digitized on ImageScannerTM III scanner (GE Healthcare Bio-sciences, Germany) using software LabScan, version 6.0 (GE Healthcare Bio-sciences, Germany) application that is specialized for acquisition of 2-DE gel images. To ensure linearity of response and minimize software-induced variance in gel image analysis, calibration of the scanner was performed before scans using provided step tablet. Gels were scanned at $300 \mathrm{dpi}$ resolution and saved in tiff format. Analysis of 2-DE gel images was performed using originally developed software prototype with new pre-processing, alignment, segmentation and subsequent analysis algorithms. All required tools were implemented using programming language MATLAB (The MathWorks, USA). Employed software tools allow: to crop gel images in order to keep only protein separation area; align images; automatically detect protein spots; manually edit protein spot area to eliminate false positives and false negatives if needed; quantify spots and estimate expression changes; visualize gel regions in 3-D or 2-DE. The process of 2-DE gel image analysis can be performed in two basic ways: spot detection and delineation are performed prior to image alignment, or in the reversed order (Dowsey et al., 2010). The following sequence of gel image analysis steps was used: image pre-processing, image alignment, spot detection with segmentation in registered images and differential analysis. Differential analysis provides ratios of normalized spot quantities that describe differences between experimental groups; changes of spot abundance between the gel groups (Treigytè et al., 2014).

\section{Results and discussion}

Creation and characterization of two-dimensional electrophoresis (2-DE) protein gel maps. In this study, the proteins in bee- and manuallycollected pollen samples was determined. Proteins from pollen were separated on 2-DE system, visualized and mass spectrometry analysis was performed. Results of comparative 2-DE gel (Fig. 1) image analysis with identified proteins are summarized in Table.
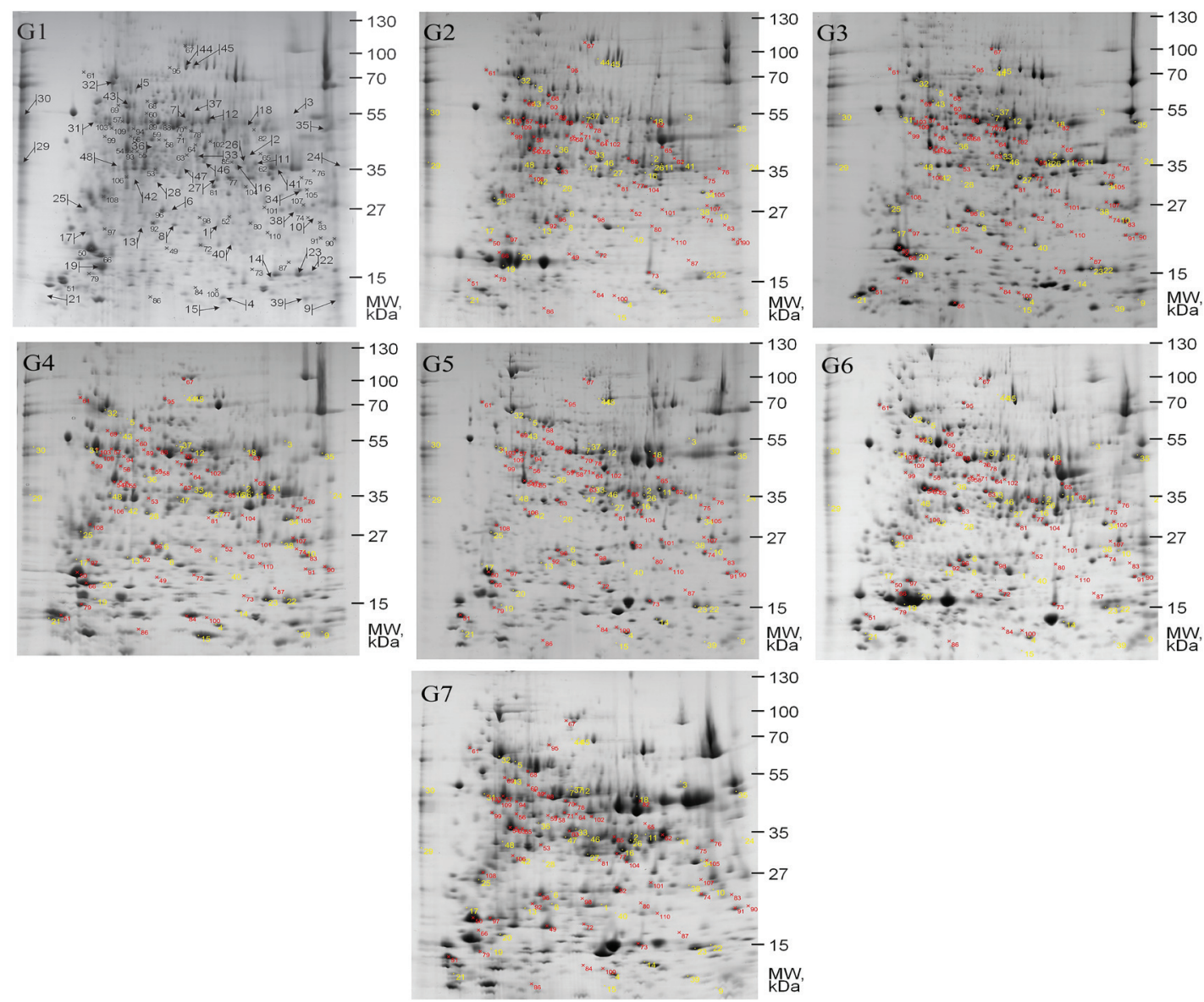

Note. Proteins were fractionated by 2-DE, collected from: G1 - Prunus and Salix spp. mixture of monofloral orchard pollen collected by bees, G2 - monofloral Prunus pollen collected by bees, G3-G7 - manually-collected pollen: G3 - Pyrus, G4 - Malus sylvestris, G5 - Prunus / Cerasus, G6 - Prunus, G7 - Prunus avium.

Figure 1. Protein isolation by two-dimensional electrophoresis (2-DE) gel (isoelectric point 3-11, gradient 5-18\%) 
Table. Proteins identified from two-dimensional electrophoresis (2-DE) gel by mass spectrometry and their potential biological function

\begin{tabular}{|c|c|c|c|c|c|c|c|c|c|c|c|c|c|}
\hline \multirow[t]{3}{*}{ No. } & \multirow{3}{*}{$\begin{array}{l}\text { Accesion } \\
\text { number }\end{array}$} & \multirow{3}{*}{ Description of protein } & \multicolumn{2}{|c|}{$\begin{array}{l}\text { Theore- } \\
\text { tical }\end{array}$} & \multicolumn{2}{|c|}{$\begin{array}{l}\text { Experi- } \\
\text { mental }\end{array}$} & \multirow{3}{*}{$\mathrm{G} 1: \mathrm{G} 2$} & \multirow[t]{3}{*}{ G1:G3 } & \multirow[t]{3}{*}{ G1:G4 } & \multirow[t]{3}{*}{ G1:G5 } & \multirow{3}{*}{ G1:G6 } & \multirow[t]{3}{*}{$\mathrm{G} 1: \mathrm{G} 7$} & \multirow[t]{3}{*}{ G2:G6 } \\
\hline & & & MW, & $\mathrm{pI}$ & MW, & $\mathrm{pI}$ & & & & & & & \\
\hline & & & \multicolumn{2}{|c|}{$\mathrm{kDa}$} & \multicolumn{2}{|c|}{$\mathrm{kDa}$} & & & & & & & \\
\hline 1 & 2 & 3 & 4 & 5 & 6 & 7 & 8 & 9 & 10 & 11 & 12 & 13 & 14 \\
\hline \multicolumn{14}{|c|}{ Transcription function } \\
\hline 2 & Q9SSE5 & $\begin{array}{l}\text { Zinc finger protein } \\
\text { CONSTANS-LIKE } 9\end{array}$ & 40.7 & 5.8 & 40.6 & 8.4 & -1.99 & -1.67 & 1.14 & -1.32 & -1.52 & -2.59 & 1.31 \\
\hline 4 & Q9C7C3 & $\begin{array}{l}\text { Zinc finger } \mathrm{CCCH} \text { domain- } \\
\text { containing protein } 36\end{array}$ & 25.9 & 9.5 & 12.7 & 7.8 & -1.05 & -1.39 & -2.18 & -1.60 & -1.61 & -1.30 & -1.53 \\
\hline 20 & Q9MAT5 & $\begin{array}{l}\text { Protein arginine } \\
\text { N-methyltransferase PRMT10 }\end{array}$ & 43.1 & 5.1 & 16.9 & 4.7 & -5.08 & -2.97 & -1.21 & -2.53 & -2.07 & -2.39 & 2.45 \\
\hline 32 & Q9LKR3 & $\begin{array}{l}\text { Mediator of RNA polymerase II } \\
\text { transcription subunit } 37 \mathrm{a}\end{array}$ & 73.5 & 5.0 & 79.2 & 4.9 & -1.10 & 1.58 & -2.07 & 1.46 & -1.04 & 1.39 & 1.06 \\
\hline 33 & Q9SR07 & $\begin{array}{l}\text { Probable WRKY transcription } \\
\text { factor } 39\end{array}$ & 36.6 & 9.4 & 37.6 & 7.3 & -1.12 & -2.60 & -1.63 & -1.33 & -2.05 & -5.43 & -1.83 \\
\hline 34 & P25209 & $\begin{array}{l}\text { Nuclear transcription factor Y } \\
\text { subunit B }\end{array}$ & 18.9 & 5.9 & 28.3 & 10 & -1.21 & -5.07 & -1.61 & -1.63 & -2.27 & -3.26 & -1.88 \\
\hline 47 & P13911 & $\begin{array}{l}\text { DNA-directed RNA polymerase } \\
\text { subunit alpha }\end{array}$ & 38.9 & 7.2 & 36.9 & 5.7 & 1.11 & -1.73 & -7.20 & -1.10 & -3.11 & -6.61 & -3.44 \\
\hline \multicolumn{14}{|c|}{ Translational function } \\
\hline 1 & Q8M9W2 & $\begin{array}{l}\text { 30S ribosomal protein } \mathrm{S} 4 \text {, } \\
\text { chloroplastic }\end{array}$ & 23.6 & 11 & 20.3 & 7.6 & 1.21 & -1.15 & 1.75 & 2.41 & 3.16 & 1.68 & 2.61 \\
\hline 11 & P49397 & $40 \mathrm{~S}$ ribosomal protein $\mathrm{S} 3 \mathrm{a}$ & 29.7 & 9.8 & 36.4 & 8.7 & -1.96 & -3.96 & -5.26 & -2.61 & -3.43 & 1.65 & -1.75 \\
\hline 37 & A7M955 & Plastid 30S ribosomal protein S2 & 26.8 & 9.8 & 60 & 6.9 & -2.76 & -1.59 & -2.08 & -1.74 & -1.53 & -1.51 & 1.80 \\
\hline 39 & A1EA43 & $\begin{array}{l}\text { Translation initiation factor IF-1, } \\
\text { chloroplastic }\end{array}$ & 12.4 & 9.5 & 12.2 & 8.4 & 14.0 & 4.14 & 1.04 & 3.62 & 4.04 & 1.31 & -3.48 \\
\hline 43 & P29197 & $\begin{array}{l}\text { Chaperonin CPN60, } \\
\text { mitochondrial }\end{array}$ & 61.2 & 5.6 & 65.6 & 5.1 & 6.54 & 1.31 & 5.49 & 2.22 & 10.8 & 11.4 & 1.66 \\
\hline \multicolumn{14}{|c|}{ Involved in flowering } \\
\hline 2 & Q9SSE5 & $\begin{array}{l}\text { Zinc finger protein } \\
\text { CONSTANS-LIKE } 9\end{array}$ & 40.7 & 5.8 & 40.6 & 8.4 & -1.99 & -1.67 & 1.14 & -1.32 & -1.52 & -2.59 & 1.31 \\
\hline \multicolumn{14}{|c|}{ Involved in photosynthesis } \\
\hline 3 & Q84RQ7 & NifU-like protein 3 , chloroplastic & 25.6 & 6.4 & 60.1 & 9.3 & 1.05 & 1.08 & -5.22 & -1.76 & -2.77 & -1.40 & -2.91 \\
\hline 4 & P17229 & $\begin{array}{l}\text { Photosystem I reaction centre } \\
\text { subunit IX (fragment) }\end{array}$ & 1.51 & 8.3 & 12.7 & 7.8 & -1.05 & -1.39 & -2.18 & -1.60 & -1.61 & -1.30 & -1.53 \\
\hline \multicolumn{14}{|c|}{ Structural proteins } \\
\hline 14 & O04725 & Profilin & 14.1 & 4.8 & 14.2 & 8.8 & -2.04 & 11.8 & -1.40 & -2.84 & -1.91 & -2.15 & 1.07 \\
\hline 31 & Q9ZRB0 & Tubulin beta- 3 chain & 49.9 & 4.6 & 50 & 5 & -2.74 & -1.68 & -2.03 & -1.77 & -1.84 & -2.29 & 1.48 \\
\hline \multicolumn{14}{|c|}{ Involved in metabolism / biosynthesis / transport } \\
\hline 5 & Q39442 & $\begin{array}{l}\text { V-type proton ATPase catalytic } \\
\text { subunit A }\end{array}$ & 68.5 & 5.1 & 71.2 & 5.4 & -1.19 & 4.38 & 5.71 & 2.16 & 1.01 & -1.21 & 1.20 \\
\hline 7 & Q1WIQ6 & $\begin{array}{l}\text { NADP-dependent } \\
\text { glyceraldehyde-3-phosphate } \\
\text { dehydrogenase }\end{array}$ & 53.0 & 6.2 & 54.7 & 6.8 & 1.01 & -1.53 & 1.38 & 7.91 & 1.35 & 2.27 & 1.33 \\
\hline 10 & $\mathrm{O} 23948$ & V-type proton ATPase subunit E & 27.1 & 6.5 & 23.9 & 10 & -1.37 & 1.31 & -2.28 & -1.11 & -3.25 & -1.54 & -2.37 \\
\hline 12 & Q40255 & $\begin{array}{l}\text { Probable aldehyde } \\
\text { dehydrogenase }\end{array}$ & 60.9 & 6.8 & & & & & & & & & \\
\hline 12 & Q8VZC3 & $\begin{array}{l}\text { Delta-1-pyrroline-5-carboxylate } \\
\text { dehydrogenase } 12 \mathrm{~A} 1 \text {, } \\
\text { mitochondrial }\end{array}$ & 61.7 & 6.2 & 54.6 & 7.2 & 3.62 & 2.18 & 1.37 & 1.73 & 1.65 & 5.11 & -2.19 \\
\hline 15 & Q10SX6 & Arsenate reductase 2.2 & 14.3 & 5.7 & 11.4 & 7.6 & 1.02 & -1.43 & -85.4 & -3.30 & -1.35 & -1.28 & -1.37 \\
\hline 16 & P26517 & $\begin{array}{l}\text { Glyceraldehyde-3-phosphate } \\
\text { dehydrogenase } 1 \text {, cytosolic }\end{array}$ & 36.49 & 6.67 & 34.2 & 8 & 1.28 & -6.98 & -5.10 & -4.89 & -1.22 & -8.05 & -1.57 \\
\hline 17 & Q9SH25 & $\begin{array}{l}\text { Putative flavin-containing } \\
\text { monooxygenase } \\
\text { FMO GS-OX-like } 11\end{array}$ & 18.756 & 8.76 & 20.9 & 4.1 & 16.8 & -6.28 & -6.42 & -1.94 & -2.61 & -2.41 & -43.9 \\
\hline 18 & Q9LKG7 & $\begin{array}{l}\text { UTP-glucose-1-phosphate } \\
\text { uridylyltransferase }\end{array}$ & 51.5 & 5.9 & 52 & 8.1 & -7.24 & 1.04 & -9.23 & -29.6 & -8.13 & -14.4 & -1.12 \\
\hline 19 & Q9SH25 & $\begin{array}{l}\text { Putative flavin-containing } \\
\text { monooxygenase } \\
\text { FMO GS-OX-like } 11\end{array}$ & 18.7 & 8.7 & 14.7 & 4.6 & -2.99 & -3.03 & 1.75 & 2.35 & -4.38 & 7.31 & -1.46 \\
\hline 26 & O65735 & $\begin{array}{l}\text { Fructose-bisphosphate aldolase, } \\
\text { cytoplasmic isozyme }\end{array}$ & 38.4 & 6.2 & 36.6 & 8.2 & -1.22 & -3.57 & -4.63 & -2.81 & -2.43 & -2.17 & -1.99 \\
\hline 27 & Q1PEY5 & $\begin{array}{l}\text { Probable 3-hydroxyisobutyryl- } \\
\text { CoA hydrolase } 2\end{array}$ & 42.2 & 7.6 & 33.2 & 7.2 & 2.90 & -1.99 & -2.11 & 2.03 & -1.64 & -2.25 & -4.76 \\
\hline 27 & Q84KK6 & $\begin{array}{l}\text { Isoflavone } \\
\text { 4'-O-methyltransferase }\end{array}$ & 40.8 & 5.4 & 33.2 & 7.2 & 2.90 & -1.99 & -2.11 & 2.03 & -1.64 & -2.25 & -4.76 \\
\hline 27 & Q42592 & $\begin{array}{l}\text { L-ascorbate peroxidase S, } \\
\text { chloroplastic / mitochondrial }\end{array}$ & 40.3 & 8.3 & 33.2 & 7.2 & 2.90 & -1.99 & -2.11 & 2.03 & -1.64 & -2.25 & -4.76 \\
\hline 27 & Q9C534 & F-box protein At1g30200 & 41.8 & 5.3 & 33.2 & 7.2 & 2.90 & -1.99 & -2.11 & 2.03 & -1.64 & -2.25 & -4.76 \\
\hline 28 & Q9C534 & Putative fructokinase-5 & 34.6 & 6.9 & 31.2 & 6.1 & 1.36 & 2.37 & -5.89 & 3.82 & 2.43 & 2.03 & 1.79 \\
\hline
\end{tabular}


Table continued

\begin{tabular}{|c|c|c|c|c|c|c|c|c|c|c|c|c|c|}
\hline 1 & 2 & 3 & 4 & 5 & 6 & 7 & 8 & 9 & 10 & 11 & 12 & 13 & 14 \\
\hline 29 & Q09054 & $\begin{array}{l}\text { Glyceraldehyde-3-phosphate } \\
\text { dehydrogenase } 2 \text {, cytosolic }\end{array}$ & 36.5 & 6.4 & 34.6 & 2.9 & 1.60 & 2.72 & 3.10 & 1.62 & 2.64 & 6.93 & 1.65 \\
\hline 30 & Q9LEI9 & Enolase 2 & 47.8 & 5.9 & 55 & 3 & 1.51 & 4.44 & 1.64 & 3.21 & 1.83 & 10.0 & 1.21 \\
\hline 32 & Q03685 & Luminal-binding protein 5 & 73.6 & 5.0 & 79.2 & 4.9 & -1.10 & 1.58 & -2.07 & 1.46 & -1.04 & 1.39 & 1.06 \\
\hline 35 & Q6ID99 & $\begin{array}{l}\text { Outer envelope pore protein } \\
21 \mathrm{~A} \text {, chloroplastic }\end{array}$ & 19.7 & 9.5 & 52.9 & 10 & -1.39 & -1.69 & 1.00 & -2.27 & -1.79 & -1.80 & -1.29 \\
\hline 36 & Q84QK0 & 12-oxophytodienoate reductase 1 & 42.4 & 5.7 & 42.1 & 5.7 & -1.58 & -1.74 & -1.75 & -1.66 & -1.31 & 1.03 & 1.21 \\
\hline 40 & Q39056 & $\begin{array}{l}\text { Cyclic pyranopterin } \\
\text { monophosphate synthase } \\
\text { accessory protein, mitochondrial }\end{array}$ & 29.4 & 8.2 & 18.6 & 6.3 & 3.85 & -3.91 & 4.70 & 4.52 & 2.87 & 7.63 & -1.34 \\
\hline 41 & F6HDM2 & $\begin{array}{l}\text { ATP-dependent (S)-NAD(P) } \\
\text { H-hydrate dehydratase }\end{array}$ & 38.0 & 8.3 & 36.4 & 7.1 & 1.06 & -1.18 & 2.13 & -1.51 & 1.25 & -1.25 & 1.18 \\
\hline 42 & Q9SID0 & Probable fructokinase-1 & 35.2 & 5.3 & 32.9 & 5.2 & -1.00 & -2.91 & -5.04 & -1.96 & -2.35 & -3.14 & -2.34 \\
\hline 44 & O50008 & $\begin{array}{l}\text { 5-methyltetrahydropteroyltri- } \\
\text { glutamatehomocysteine } \\
\text { methyltransferase } 1\end{array}$ & 84.3 & 6.0 & 89.6 & 5.8 & 7.74 & 7.02 & 53.7 & 33.3 & 59.4 & 25.8 & 7.67 \\
\hline 45 & O50008 & $\begin{array}{l}\text { 5-methyltetrahydropteroyltri- } \\
\text { glutamatehomocysteine } \\
\text { methyltransferase } 1\end{array}$ & 84.3 & 6.0 & 89.3 & 5.8 & -2.05 & -1.23 & 17.5 & 4.03 & 3.28 & 9.92 & 6.73 \\
\hline 48 & Q38799 & $\begin{array}{l}\text { Pyruvate dehydrogenase E1 } \\
\text { component subunit beta-1, } \\
\text { mitochondrial }\end{array}$ & 39.1 & 5.6 & 36.1 & 5 & -1.11 & -2.47 & -7.64 & 1.57 & 1.34 & -1.41 & 1.48 \\
\hline \multicolumn{14}{|c|}{ Unknown biological function } \\
\hline 6 & P01060 & $\begin{array}{l}\text { Bowman-Birk type proteinase } \\
\text { inhibitor } 2\end{array}$ & 11.6 & 5.17 & 25.1 & 5.9 & -7.12 & -2.57 & -3.94 & -1.25 & -8.55 & 1.13 & -1.20 \\
\hline 8 & Q8L8Z1 & CASP-like protein At4g15630 & 20.0 & 9.9 & 20.5 & 6.1 & 2.38 & -1.92 & -2.12 & 1.39 & 1.22 & 1.95 & -1.94 \\
\hline 9 & Q852K5 & $\begin{array}{l}\text { Zinc finger A20 and AN1 } \\
\text { domain-containing stress- } \\
\text { associated protein } 6\end{array}$ & 17.5 & 8.9 & 11.8 & 11 & 4.00 & 1.78 & -3.47 & 2.31 & 1.57 & 5.60 & -2.55 \\
\hline 13 & Q17TI5 & Protein BREVIS RADIX & 38.7 & 6.3 & 20.4 & 5.4 & -1.15 & -1.45 & -4.36 & -2.26 & -1.35 & -1.81 & -1.17 \\
\hline 21 & P24924 & Trypsin inhibitor & 19.5 & 6.2 & 12.6 & 3.1 & -3.47 & -11.3 & -14.3 & -6.41 & -5.94 & -4.65 & -1.71 \\
\hline 22 & P01060 & $\begin{array}{l}\text { Bowman-Birk type proteinase } \\
\text { inhibitor } 2\end{array}$ & 11.6 & 5.1 & 14.9 & 9.9 & 1.57 & -2.08 & -2.63 & -1.15 & 1.08 & 1.25 & -1.46 \\
\hline 23 & P38475 & $\begin{array}{l}\text { Uncharacterized mitochondrial } \\
\text { protein ymf33 }\end{array}$ & 15.5 & 8.4 & 15 & 9.7 & 3.82 & 1.48 & -1.09 & 1.31 & 1.08 & -1.10 & -3.53 \\
\hline 24 & Q9C7M1 & $\begin{array}{l}\text { Putative FBD-associated F-box } \\
\text { protein At1g55030 }\end{array}$ & 48.1 & 8.6 & 37.8 & 10 & 3.50 & 8.00 & 3.38 & 1.41 & 11.6 & 1.22 & 3.33 \\
\hline 25 & P93208 & $14-3-3$ protein 2 & 28.8 & 4.7 & 25.4 & 4.2 & -3.58 & -1.08 & 1.11 & -1.31 & -1.17 & -1.43 & 3.05 \\
\hline 33 & Q6NPC9 & $\begin{array}{l}\text { Probable RNA methyltransferase } \\
\text { At5g51130 }\end{array}$ & 36.5 & 9.2 & 37.6 & 7.3 & -1.12 & -2.60 & -1.63 & -1.33 & -2.05 & -5.43 & -1.83 \\
\hline 38 & Q9T0J4 & $\begin{array}{l}\text { Putative F-box protein } \\
\text { At4g } 38870\end{array}$ & 48.3 & 9.6 & 24.4 & 9.6 & 2.76 & 2.08 & -2.39 & 1.53 & 1.30 & -1.27 & -2.12 \\
\hline 46 & Q9FHD5 & $\begin{array}{l}\text { Cysteine-rich repeat secretory } \\
\text { protein } 57\end{array}$ & 31.8 & 5.5 & 37.2 & 5.8 & -2.89 & -4.13 & -3.13 & -2.72 & -1.51 & -1.05 & 1.91 \\
\hline
\end{tabular}

Notes. No. - spot number in 2-DE gel (G1-G7), numbers in column correspond to numbering of proteins in 2-DE gel; accession number in UniProt database (UniProt Consortium, 2015), MW - molecular weight, pI - isoelectric point; G1 - Prunus and Salix spp. mixture of monofloral orchard pollen collected by bees, G2 - monofloral Prunus pollen collected by bees, G3-G7 - manuallycollected pollen: G3 - Pyrus, G4 - Malus sylvestris, G5 - Prunus / Cerasus, G6 - Prunus, G7 - Prunus avium. Changes in protein spot volumes are represented as ratios of averages of normalized spot volumes (Gx:Gy); an increase in spot abundance is represented with positive fold change and a decrease, with a negative fold change.

Protein spots in maps were overlapped and quantitative changes in protein levels were evaluated by computer assisted analysis (Table). Numbers (No.) in the 2-DE maps indicate the positions of proteins subjected to mass spectrometry analysis. Spot labels (No.) are the same as in Table. Representative images from one of the three experiments showing similar results are shown. A total of 48 proteins were identified by mass spectrometry. Their changes in various orchard pollen samples were designated and grouped according to cellular function (Table). Ratios of normalized spot quantities along with the experimental molecular weight (MW) and isoelectric point $(\mathrm{pI})$ data were estimated. Identified proteins are marked with corresponding labels in Figure 2 and Table. Isoelectric points of identified proteins were determined according to known $\mathrm{pI}$ values of the used $\mathrm{pI}$ standard 3-11. Molecular weights of protein spots were computed by comparing (using a standard curve) their relative motilities to relative motilities of the marker proteins (standards) whose molecular weight is known. Changes in protein spot volumes are represented as ratios of averages of normalized spot volumes, currently designing Gx:Gy. An increase in spot abundance is represented with positive fold change and a decrease, with a negative fold change. Table summarizes changes that were determined between protein maps of G1-G7 (Fig. 1). Twenty eight proteins were up- (increase) or down-regulated (decrease) in different pollen samples more than five times (Table).

Protein three-dimensional (3-D) visualization and description of potential function of identified proteins in different pollen samples. About 50 proteins in the pollen of different origin was indentified. Most (27) of the identified proteins are involved in metabolic and biosynthesis processes and molecule transport (Table, Fig. 2). A few proteins - subunits of V-type proton ATPase which play a role in metabolism was identified (Table, No. 5 Q39442 and No. 10 O23948). It was shown in literature that V-ATPase function is essential for Golgi organization and development of the male gametophyte (pollen), plant growth via V-ATPasedependent endosomal trafficking (Zhou et al., 2016). 
Other enzymes involved in metabolic process such NADP-dependent glyceraldehyde-3-phosphate dehydrogenase (Table, No.7 Q1WIQ6 and No. 16 P26517), delta-1-pyrroline-5-carboxylate dehydrogenase (Table, No.12 Q8VZC3), monooxygenase (Table, Nos 17 and 19 Q9SH25), pyruvate dehydrogenase E1 (Table, No. 48 Q38799), probable aldehyde dehydrogenase (Table, No.12 Q8VZC3), were also found with changed expression levels between different pollen samples. Mostly four enzymes, such as catalase, superoxide dismutase, alcohol dehydrogenase and pyruvate decarboxylase, are believed to play a central role against oxidative stress in plants during photosynthesis and respiration (Alscher et al., 2002). Seven proteins (Q9SSE5, Q9C7C3, Q9MAT5, Q9LKR3, Q9SR07, P25209 and P13911) are involved in transcription and five (Q8M9W2, P49397, A7M955, A1EA43 and $\mathrm{P} 29197)$ - in translation processes. The 11 proteins with unknown function was identified (Table, Fig.2).

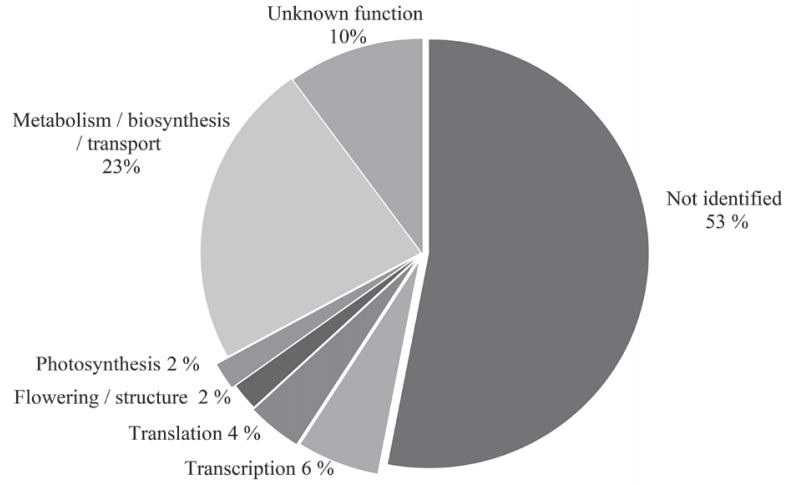

Figure 2. The distribution of proteins, identified by mass spectrometry after two-dimensional electrophoresis (2-DE) gel, according to their biological function

Having assessed all the relationships Gx:Gy in protein spot volumes it was found that some quantities of particular protein type vary more than 10 times. The following proteins were selected from the highest to lowest protein spot volumes ratio for their spots: No. 15 (arsenate reductase), No. 44-45 (5-methyltetrahydropteroyltriglutamate), No. 18 (UTPglucose-1-phosphate uridylyltransferase), No. 17 (putative flavin-containing monooxygenase), No. 21 (trypsin inhibitor), No. 39 (translation initiation factor IF-1), No. 14 (profilin), No. 24 (putative FBD-associated F-box protein) and No. 43 (chaperonin CPN60). The automatic spot matching fails in such situations and the exact position of small protein spot was noticed only in 3-D view of the gel, followed by stereoscopic visualization. A 3-D visualization of matched and identified protein spots is shown in Figure 3.

Proteins identified in spots $(14-18,21,24$ 39 and 43-45) were overlapped in maps. Quantitative changes of proteins were evaluated by a computerassisted analysis (Table 1) and the 3-D view of those protein spots was composed additionally by the mass spectrometry analysis. The identified protein fold change described above was $\geq 5$.

Arsenate reductase (glutaredoxin) (Table, spot No. 15 Q10SX6) was overexpressed only in the sample from Malus sylvestris pollen. Arsenate reductase protein is required for arsenate resistance (Abbas et al., 2018). It was shown that absence of arsenic reductase in Arabidopsis results in accumulation of arsenic 10- to 16 -fold more compared with wild-type plants and this can lead to toxic effects on pollen tube development (Dhankher et al., 2006). The Food Standards Agency's final report provides data on the concentration of arsenic in fruit and vegetables. Arsenic was in low concentration
(1- $6.7 \mathrm{ng} \mathrm{g}^{-1}$ fresh weight) in apple samples compared with other fruits and vegetables, which can be due to high arsenate reductase expression (Meharg et al., 2012).

Another protein, identified by mass spectrometry, whose protein spot volumes varies from 7.02 to 59.4 in different pollen samples, but predominates mostly in G1 sample, is 5-methyltetrahydropteroyltriglutamatehomocysteine methyltransferase 1 (Table, Fig. 3, spot No. 44 O50008). This protein is involved in the pathway that synthesizes L-methionine - sulphurcontaining amino acid required for protein synthesis (Ravanel et al., 2004). Methionine is the only sulphurcontaining amino acid that is essential for mammals and must therefore be derived entirely from the diet. Methionine can be found in pollen of different plants.

UTP-glucose-1-phosphate uridylyltransferase (Table and Fig. 3, spot No. 18 Q9LKG7) was found in high expression levels in G4-G7 samples. In plant leaves, UTP-glucose-1-phosphate uridylyltransferase is a key part of the sucrose biosynthesis pathway. Also, this enzyme is essential for microgametophyte development during which the pollen reaches mature stage and desiccates (Wang et al., 2008).

Studies have revealed variation in expression of putative flavin-containing monooxygenase FMO GSOX-like 11 protein (Table, spot No. 17): low expression in bee-collected samples from orchard and Prunus pollen (G1 and G2) and high expression in hand-collected samples from pollen of Pyrus communis pollen (G3) and Malus sylvestris (G4). It has been shown that its structure is similar to flavin-containing monooxygenase FMO from Arabidopsis. In literature, the data suggesting that over-expression of three FMO, a class of enzymes whose function in plants has been uncharacterized so far, resulted in resistance to pathogens can be found (Koch et al., 2006).

It was found fold changes in expression of proteins whose biological function in pollen is unknown: trypsin inhibitor (spot No. 21, P24924) and putative FBD-associated F-box protein At1g55030 (Table, Fig. 3, spot No. 24, Q9C7M1).

Translation initiation factor IF-1 protein - one of the essential components for the initiation of protein synthesis in chloroplasts - was more expressed in G1, G4 and G7 pollen samples than in G2-G3 and G5-G6 samples (Table, Fig. 3, spot No. 39 A1EA43). Somehow translation initiation factor IF-1 protein expression is higher and probably synthesis of pollen proteins is better in $M$. sylvestris and $P$. avium samples for unknown reasons.

The ratios of normalized spot quantities of profilin differ among the pollen of experimental groups (Table, Fig. 3, spot No. 14 O04725). It was found a small level of profilin protein in the sample of $P$. communis pollen collected by hand (G3) in comparison with all other samples. Arabidopsis profilins, low- $M_{\mathrm{r}}$ actin monomer-binding proteins, were shown to play a role in cell elongation, cell shape maintenance, polarized growth of root hair and in determination of flowering time. Profilins are present in all eukaryotic cells and are identified as allergens in pollen (birch, grass, etc.), latex and plant foods (Ramachandran et al., 2000). So far only four proteins have been identified as Pyrus allergens: pathogenesis-related protein PR-10, nonspecific lipidtransfer protein 1 , isoflavone reductase related protein and profilin. Actually, this genus is not commonly cited as a source of pollinosis. Only one study demonstrated that direct, prolonged contact with the pollen could cause eye allergy symptoms in a few individuals. Maybe it is the reason why in our samples, only in the Pyrus pollen sample was found very low amount of profilin (Yanagisawa et al., 1999).

One of the proteins, detected with some differences between the pollen samples, is chaperonin CPN60 (Table 1, Fig. 3, spot No. 43 P29197). It was found CPN60 in low amount in G4 (M. sylvestris) and 


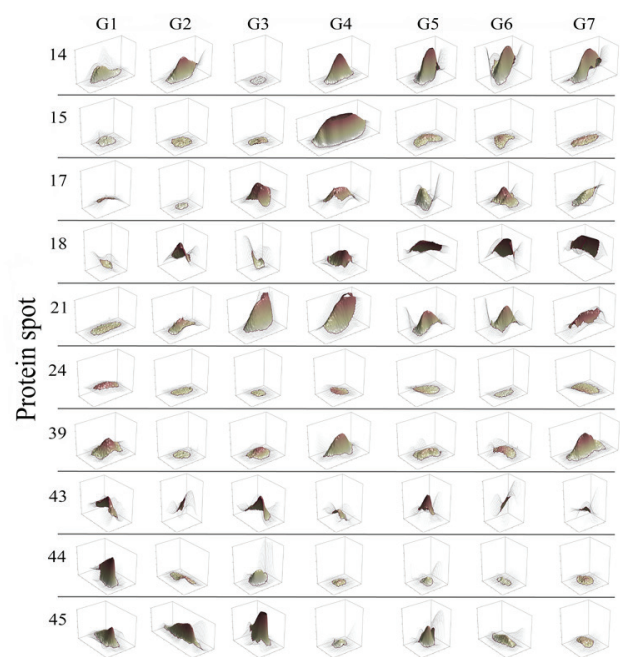

Note. Proteins from: G1 - Prunus and Salix spp. mixture of monofloral pollen collected by bees, G2 - monofloral Prunus (plum) pollen collected by bees; manually-collected pollen: G3 - Pyrus, G4 - Malus sylvestris, G5 - Prunus / Cerasus, G6 - Prunus, G7 - Prunus avium.

Figure 3. Protein expression changes in G1-G7 pollen samples

G7 ( $P$. avium) pollen samples. In plants, the chloroplast CPN60 was initially identified as a protein which is very important for folding of Rubisco assembly, the key enzyme responsible for respiration (Zhao, Liu, 2018). It was found data in literature that silencing CPN21 in grape seed led to grape seed abortion (Hanania et al., 2007).

In summary, 2-DE protein maps of pollen of different botanical origin collected by hand or by bees, evaluated changes in protein spot quantity, identified about 50 specific proteins and described their potential functions was compared.

\section{Conclusions}

1. In this study, for the first time, the reference maps of the bee- and manually-collected orchard pollen proteome by using protein extraction technique followed by a two-dimensional electrophoresis (2-DE) and mass spectrometry analysis was created. It was identified about 50 proteins from a total of $\sim 200$ protein spots.

2. The potential biological functions of these proteins vary from transcription, translation to metabolic cellular processes.

3. Different trends of the profilin expression were observed between bee- and manually-collected pollen. The data indicate that profilin expression level is not high in pollen mixture collected by bees from early blossom plants in the spring like plums, willows. Therefore, the profilin of this pollen should not cause allergic symptoms for pollen consumers.

4. All these data can be important for understanding the function and role of pollen protein which can lead to its possible application in food industry.

\section{Acknowledgments}

This research was funded by a grant (No. MIP083/2015) from the Research Council of Lithuania. The authors thank Dr. Mindaugas Valius, Dr. Algirdas Kaupinis and Dr. Marija Ger for the excellent assistance with mass spectrometry.

Received 12062018 Accepted 03032019

\section{References}

1. Abbas G., Murtaza B., Bibi I., Shahid M., Niazi N. K., Khan M. I., Amjad M., Hussain M., Natasha. 2018. Arsenic uptake, toxicity, detoxification, and speciation in plants: physiological, biochemical, and molecular aspects. International Journal of Environmental Research and Public Health, 15 (1): E59.

https://doi.org/10.3390/ijerph15010059

2. Almeida-Muradiana L. B., Pamplona L. C., Coimbra S. Barth O. M. 2005. Chemical composition and botanical evaluation of dried bee pollen pellets Journal of Food Composition and Analysis, 18: 105-111. https://doi.org/10.1016/j.jfca.2003.10.008

3. Alscher R. G., Erturk N., Heath L. S. 2002. Role of superoxide dismutases (SODs) in controlling oxidative stress in plants. Journal of Experimental Botany, 53 (372): 1331-1341. https://doi.org/10.1093/jexbot/53.372.1331

4. Borutinskaite V., Treigyte G., Ceksteryte V., Kurtinaitiene B., Navakauskiene R. 2018. Proteomic identification and enzymatic activity of buckwheat (Fagopyrum esculentum) honey based on different assays. Journal of Food and Nutrition Research, 57 (1): 57-69.

5. Čeksterytè V. 2012. Plant pollen found in Lithuanian honey. An electronic catalogue [CD]. Lietuvos Respublikos žemès ūkio ministerija, Vilnius (in Lithuanian). ISBN: 978-9955-650-44-7

6. Čeksterytė V., Navakauskienė R., Treigytė G., Jansen E., Kurtinaitienè B., Dabkevičienė G., Balžekas J. 2016. Fatty acid profiles of monofloral clover beebread and pollen and proteomics of red clover (Trifolium pratense) pollen. Bioscience, Biotechnology, and Biochemistry, 80 (11): 2100-2108. https://doi.org/10.1080/09168451.2016.1204218

7. Conti I., Medrzycki P., Argenti Ch., Meloni M. Vecchione V., Boi M., Mariotti M. G. 2016. Sugar and protein content in different monofloral pollens - building a database. Bulletin of Insectology, 69 (2): 318-320.

8. Dai S. J., Li, L., Chen T. T., Chong K., Xue Y., Wang T. 2006. Proteomic analyses of Oryza sativa mature pollen reveal novel proteins associated potentially with pollen germination and tube growth. Proteomics, 6: 2504-2529. https://doi.org/10.1002/pmic.200401351

9. Dhankher O. P., Rosen B. P., McKinney E. C., Meagher R. B. 2006. Hyper accumulation of arsenic in the shoots of Arabidopsis silenced for arsenate reductase (ACR2). Proceedings of the National Academy of Sciences of the United States of America, 103: 5413-5418 https://doi.org/10.1073/pnas.0509770102

10. Dowsey A. W., English J. A., Lisacek F., Morris J. S., Yang G. Z., Dunn M. J. 2010. Image analysis tools and emerging algorithms for expression proteomics. Proteomics, 10 (23): 4226-4257. https://doi.org/10.1002/pmic.200900635

11. Gracham J. M. 1992. The hive and the honey bee, 1324 p.

12. Hanania U., Velcheva M., Or E., Flaishman M., Sahar N., Perl A. 2007. Silencing of chaperonin 21, that was differentially expressed in inflorescence of seedless and seeded grapes, promoted seed abortion in tobacco and tomato fruits. Transgenic Research, 16 (4): 515-525. https://doi.org/10.1007/s11248-006-9044-0

13. Holmes-Davis R., Tanaka C. K., Vensel W. H., HurkmanW. J., McCormick S. 2005. Proteome mapping of mature pollen of Arabidopsis thaliana. Proteomics, 5 (18): 4864-4884. https://doi.org/10.1002/pmic.200402011

14. Kędzia B. 2008. Chemical composition and adaptogenic activity of honeybee-collected pollen. Part I. Chemical composition. Postępy Fitoterapii, 1: 47-58 (in Polish)

15. Koch M., Vorwerk S., Masur C., Sharifi-Sirchi G., Olivieri N., Schlaic N. L. 2006. A role for a flavincontaining mono-oxygenase in resistance against microbial pathogens in Arabidopsis. The Plant Journal, 47: 629-639. https://doi.org/10.1111/j.1365-313X.2006.02813.x

16. Komosinska-Vassev K., Olczyk P., Kaźmierczak J. Mencner L., Olczyk K. 2015. Bee pollen: chemical composition and therapeutic application. Evidence-Based Complementary and Alternative Medicine, 2015, $6 \mathrm{p}$. https://doi.org/10.1155/2015/297425

17. Leonhardt S. D., Blüthgen N. 2012. The same, but different: pollen foraging in honeybee and bumblebee colonies. Apidologie, 43: 449-464. https://doi.org/10.1007/s13592-011-0112-y

18. Li J., Chen J., Zhang Z., Pan Y. 2008. Proteome analysis of tea pollen (Camellia sinensis) under different storage conditions. Journal of Agricultural and Food Chemistry, 56: 7535-7544. https://doi.org/10.1021/jf800885z 
19. Louveaux J., Maurizio A., Vorwhol G. 1978. Methods of melissopalynology. Bee World, 59 (4): 139-157. https://doi.org/10.1080/0005772X.1978.11097714

20. Mauriello G., De Prisco A., Di Prisco G., La Storia A., Caprio E. 2017. Microbial characterization of bee pollen from the Vesuvius area collected by using three different traps. PLoS ONE, 12 (9): e0183208. https://doi.org/10.1371/journal.pone.0183208

21. Mayfield J. A., Fiebig A., Johnstone S. E., Preuss D. 2001 Gene families from the Arabidopsis thaliana pollen coat proteome. Science, 292: 2482-2485. https://doi.org/10.1126/science.1060972

22. Meharg A., Norton G., Mestrot A., Gn., Deacon C., Feldman J. 2012. Arsenic speciation in fruit and vegetables grown in the UK. Food Standards Agency Final Report FS241003, $74 \mathrm{p}$.

23. Negrao A. F, Orsi R. O. 2018. Harvesting season and botanical origin interferes in production and nutritional composition of bee pollen. Anais da Academia Brasileira Ciencias, 90 (1): 325-332.

https://doi.org/10.1590/0001-3765201720150192

24. Paoli P. P., Donley D., Stabler D., Saseendranath A. Nicolson S. W., Simpson S. J., Wright G. W. 2014. Nutritional balance of essential amino acids and carbohydrates of the adult worker honeybee depends on age. Amino Acids, 46 (6): 1449-1458. https://doi.org/10.1007/s00726-014-1706-2

25. Ramachandran S., Christensen H. E. M., Ishimaru Y., Dong C. H., Chao-Ming W., Cleary A. L., Chua N.H. 2000. Profilin plays a role in cell elongation, cell shape maintenance, and flowering in Arabidopsis. Plant Physiology, 124 (4): 1637-1647. https://doi.org/10.1104/pp.124.4.1637

26. Ravanel S., Block M. A., Rippert P., Jabrin S., Curien G., Rebeille F., Douce R. 2004. Methionine metabolism in plants: chloroplasts are autonomous for de novo methionine synthesis and can import S-adenosylmethionine from the cytosol. Journal of Biological Chemistry, 279: 22548-22557. https://doi.org/10.1074/jbc.M313250200

27. Sheoran I. S., Ross A. R. S., Olson D. J. H., Sawhney V. K 2007. Proteomic analysis of tomato (Lycopersicon esculentum ) pollen. Journal of Experimental Botany, 58 (13): 3525-3535. https://doi.org/10.1093/jxb/erm199

28. Shevchenko A., Wilm M., Vorm O., Mann M. 1996 Mass spectrometric sequencing of proteins silver- stained polyacrylamide gels. Analytical Chemistry, 68 (5): 850-858. https://doi.org/10.1021/ac950914h

29. Shi Y., Jiang L., Zhang L., Kang R., Yu Z. 2014. Dynamic changes in proteins during apple (Malus $\times$ domestica) fruit ripening and storage. Horticulture Research, 1 (1): 6. https://doi.org/10.1038/hortres.2014.6

30. Tidke J. A., Nagarkar S. S. 2015. Pollen spectrum and biochemical analysis of dominant pollen types represented by local honey samples. International Journal of Pharma Research and Review, 4 (5): 21-33.

31. Treigyte G., Zaikova I., Matuzevičius D., Čeksterytè V., Dabkevičienè G., Kurtinaitienė B., Navakauskienė R. 2014. Comparative proteomic analysis of pollen of Trifolium pratense, T. alexandrinum and T. repens. ZemdirbysteAgriculture, 101 (4): 453-460. https://doi.org/10.13080/z-a.2014.101.058

32. UniProt Consortium. 2015. UniProt: a hub for protein information. Nucleic Acids Research, 43: D204-D212. https://doi.org/10.1093/nar/gku989

33. Wang R., Shen X., Zhang W. 2018. Analysis of differentially expressed proteins in the pollen of Malus spectabilis (crabapples) and Malus domestica ('Gala' apples) and their role in pollination. The Journal of Horticulture Science and Biotechnology, 93 (6): 566-572. https://doi.org/10.1080/14620316.2018.1433965

34. Wang Y., Zhang W. Z., Song L. F., Zou J. J., Su Z., $\mathrm{Wu}$ W. H. 2008. Transcriptome analyses show changes in gene expression to accompany pollen germination and tube growth in Arabidopsis. Plant Physiology, 148 (3): 1201-1211.https://doi.org/10.1104/pp.108.126375

35. Yanagisawa S., Nagaki Y., Hiraki S., Kadoi C., Hayasaka S., Teranishi H. 1999. Seasonal allergic conjunctivitis induced by Japanese pear pollen. The Japanese Journal of Ophthalmology, 43 (3): 240-242. https://doi.org/10.1016/S0021-5155(99)00028-3

36. Zhao Q, Liu C. 2018. Chloroplast chaperonin: an intricate protein folding machine for photosynthesis. Frontiers in Molecular Biosciences, 4 (98). https://doi.org/10.3389/fmolb.2017.00098

37. Zhou A., Bu Y., Takano T., Zhang X., Liu S. 2016. Conserved V-ATPase c subunit plays a role in plant growth by influencing V-ATPase-dependent endosomal trafficking. Plant Biotechnology Journal, 14 (1): 271-283.

https://doi.org/10.1111/pbi.12381

ISSN 1392-3196 / e-ISSN 2335-8947

Zemdirbyste-Agriculture, vol. 106, No. 2 (2019), p. 183-190

DOI 10.13080/z-a.2019.106.024

\title{
Bičių ir rankomis surinktų žiedadulkių proteominè analizė
}

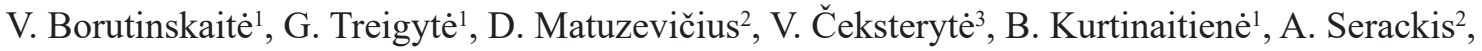 \\ D. Navakauskas ${ }^{2}$, R. Navakauskiené ${ }^{1}$
}

${ }^{1}$ Vilniaus universiteto Gyvybès mokslų centras

${ }^{2}$ Vilniaus Gedimino technikos universiteto Elektronikos fakultetas

${ }^{3}$ Lietuvos agrarinių ir miškų mokslų centro Žemdirbystés institutas

\section{Santrauka}

Sodų žiedadulkių proteomo (bendrojo baltymo) sudètis nèra išsamiai aprašyta. Straipsnyje pateikta skirtingos botaninès kilmės žiedadulkiu kiekybinė ir kokybinė proteominė analizė. Tirtos bičiu surinktos slyvų (Prunus) bei blindžių (Salix spp.) monoflorinio mišinio ir monoflorinès slyvų (Prunus) žiedadulkès. Kitos žiedadulkès buvo surinktos rankomis ankstyvą pavasarị nuo ịvairių vaismedžių nuskintų žiedų: kriaušių (Pyrus communis), obelų (Malus sylvestris), vyšnių (Prunus / Cerasus) ir trešnių (Prunus avium). Iš žiedadulkių mèginių išskirti baltymai buvo frakcionuoti taikant dvikryptę elektroforeze (2-D) ir identifikuoti taikant masiu spektrometrine analizę. Atliktas baltymų, kurių intensyvumas įvairiuose sodų žiedadulkių mėginiuose skyrèsi daugiau nei dešimt kartų, trimatis erdvinis vaizdinimas. Nustatyta, kad identifikuotų baltymų biologinès funkcijos skiriasi ir yra susijusios su transkripcija / transliacija, metaboliniais ir kitais ląsteliniais procesais.

Tyrimo duomenys atskleidè, kad fermentas 5-methyltetrahydropteroyltriglutamato-homocysteino methyltransferazė 1, dalyvaujantis metionino susidarymo procese, aptiktas visose tirtose žiedadulkèse, tačiau jo raiška didžiausia bičių surinktose vaismedžių žiedadulkèse. Rankomis surinktose žiedadulkèse nustatyta didelè baltymo flavinmonooksigenazès (angl. flavin-containing monooxygenase FMO GS-OX-like 11) raiška, kuri yra svarbi augalų apsaugai nuo patogenų, taip pat hormonų biosintezei.

Reikšminiai žodžiai: 2-D (dvikryptè) elektroforezè, 3-D vizualizacija, baltymai, masių spektrometrija, žiedadulkès. 